УДК 911.52(477.75)

ПРИМЕНЕНИЕ КОСМИЧЕСКИХ СНИМКОВ LАNDSАТ-8
ДЛЯ МОНИТОРИНГА ЛАНДШАФТОВ В ПРЕДЕЛАХ
БАХЧИСАРАЙСКОГО РАЙОНА РЕСПУБЛИКИ КРЫМ
(НА ПРИМЕРЕ РАСЧЕТА ЗНАЧЕНИЙ ВЕГЕТАЦИОННОГО
ИНДЕКСА NDУ И ТЕМПЕРАТУРЫ ПОВЕРХНОСТИ (LST))

Горбунов Р.В., Табунщик В.А., Андрончик Я.О.

ФГБУН ФИЦ «Институт биологии южных морей имени А.О. Ковалевского РАН», Севастополь, е-таil: tabunshchyk@ya.ru

На современном этапе развития науки и техники особенно актуальным становится всестороннее использование данных дистанционного зондирования Земли для решения различных народнохозяйственных задач. Космические снимки высокого разрешения являются одним из лучших инструментов для этих целей. Использование космических снимков позволяет осуществлять мониторинг различных явлений и процессов, происходящих в различных временных и пространственных масштабах, как на локальном, так и на региональном и глобальном уровнях. Особенно хорошо для этих целей подходят мультиспектральные космические снимки, в частности семейство космических снимков Landsat. Существует множество показателей, которые могут быть оценены с использованием космических снимков. В работе используются космические снимки для оценки двух показателей. Одним из показателей, который оценивается по мультиспектральным космическим снимкам, являются вегетационные индексы, среди которых наиболее распространенным является Normalized Difference Vegetation Index (NDVI), который показывает активность зеленой фитомассы растений в период съемки и показывает нарушенность растительного покрова. Еще одним показателем, который рассчитывается по мультиспектральным космическим снимкам, является температура поверхности - Landsat Surface Temperature (LST). Вместе эти показатели показывают интенсивность освоения той или иной территории. Особенно это характерно для территорий, вовлеченных в хозяйственную деятельность. В работе на примере территории Бахчисарайского района Республики Крым показана динамика изменения за 2020 г. вегетационного индекса NDVI и изменение температуры поверхности LST. Установлено, что рассматриваемые показатели изменяются на территории Бахчисарайского района Республики Крым с северо-запада на юго-восток и коррелируют с изменением абсолютных высот на рассматриваемой территории.

Ключевые слова: мониторинг, ГИС, Крым, Крымский полуостров, Landsat, NDVI, LST

\title{
APPLICATION OF LANDSAT-8 SATELLITE IMAGES FOR MONITORING LANDSCAPES WITHIN THE BAKHCHISARAI DISTRICT OF THE REPUBLIC OF CRIMEA (USING THE EXAMPLE OF CALCULATING NDVI AND LST)
}

\author{
Gorbunov R.V., Tabunschik V.A., Andronchik Ya.O. \\ A.O. Kovalevskiy Institute of Biology of the Southern Seas of RAS, \\ Sevastopol, e-mail: tabunshchyk@ya.ru
}

\begin{abstract}
At the present stage of the development of science and technology, the comprehensive use of Earth remote sensing data for solving various national economic problems is becoming especially relevant. High-resolution satellite images are one of the best tools for these purposes. The use of satellite images makes it possible to monitor various phenomena and processes occurring at various time and spatial scales, both at the local, regional and global levels. Multispectral satellite images, in particular the Landsat family of satellite images, are particularly well suited for these purposes. There are many indicators that can be estimated using satellite images. The work uses satellite images to evaluate two indicators. One of the indicators that is evaluated by multispectral satellite images are vegetation indices, among which the most common is the Normalized Difference Vegetation Index (NDVI), which shows the activity of green phytomass of plants during the shooting period and shows the disturbance of vegetation cover. Another indicator that is calculated from multispectral satellite images is the surface temperature Landsat Surface Temperature (LST). Together, these indicators show the intensity of development of a particular territory. This is especially true for territories involved in economic activity. Using the example of the territory of the Bakhchisarai district of the Republic of Crimea, the dynamics of changes in the vegetation index NDVI and the change in surface temperature LST for 2020 are shown in the work. It is established that the considered indicators change in the territory of the Bakhchisarai district of the Republic of Crimea from the northwest to the southeast and correlate with the change in absolute heights in the territory under consideration.
\end{abstract}

Keywords: monitoring, GIS, Crimea, the Crimean Peninsula, Landsat, NDVI, LST

Термин «мониторинг» со второй половины XX в. все активнее используется в научной литературе в связи с постоянным ростом хозяйственного освоения территорий и акваторий земного шара. Согласно $[1$, с. 6$]$ под мониторингом понимается «система повторных целенаправленных наблюдений за исследуемыми объектами в пространстве и времени». Географические информационные системы (ГИС) и космические снимки высокого разрешения в последние годы стали все активнее использоваться в целях 
оперативного мониторинга различных природных и антропогенных объектов [2-5]. Использование космических снимков для целей мониторинга представляет особенно актуальную задачу сейчас, при постоянно увеличивающихся потоках информации и необходимости принятия решений. Особенно остро это проявляется для территорий, которые активно используются и вовлекаются в хозяйственное развитие.

Крымский полуостров после 2014 г. испытывает особенно мощный процесс преобразования, развития и модернизации инфраструктуры, масштабы которого уже сложно оценивать традиционными методами. В связи с этим постоянно нарастает нагрузка на экосистемы и ландшафты Крымского полуострова.

Цель исследования - показать возможность применения мультиспектральных космических снимков для целей мониторинга ландшафтов в пределах Бахчисарайского района Республики Крым.

\section{Материалы и методы исследования}

Для мониторинга за вегетационным состоянием растений и определения температуры поверхности использованы космические снимки Landsat-8, которые имеют разрешение 30×30 м/пиксель, и содержат набор мультиспектральных каналов, которые являются хорошим средством для ведения мониторинга. Существенным недостатком, при высоком разрешении, является периодичность съемки, которая в среднем составляет два снимка в месяц. Однако с учетом того, что над территорией Крымского полуострова наблюдается значительная облачность, особенно в зимние месяцы, подобрать серию снимков за год не представляется возможным. В связи с этим в работе использованы выборочные космические снимки Landsat-8 за весну - осень 2020 г.

Для целей мониторинга по космическим снимкам возможно рассчитывать множество показателей, характеризующих ту или иную территорию $[6,7]$. В работе анализируется вегетационный индекс NDVI и температура поверхности, рассчитанные на основе космических снимков Landsat-8. Методика исследования изложена в работах $[8,9]$.

Расчет вегетационного индекса NDVI происходит по формуле (1) [10]:

$$
\mathrm{NDVI}=\frac{\mathrm{NIR}-\mathrm{RED}}{\mathrm{NIR}+\mathrm{RED}},
$$

где NIR - отражение в ближней инфракрасной области спектра, RED - отражение в красной области спектра.
Расчет температуры поверхности производится с использованием методики, описанной в работах [11-13], по формуле (2), с использованием 10-го канала мультиспектрального архива снимка Landsat-8, ввиду лучших результатов по сравнению с 11-м каналом, как показано в работе [14].

$$
\begin{aligned}
T= & (1321.08 /(\operatorname{Ln}((774.89 /((« B 10 . T I F\rangle * \\
& * 0.0003342)+0.1))+1)))-273.15, \quad(2)
\end{aligned}
$$

где «B10.TIF» - 10-й канал мультиспектрального архива снимка Landsat-8 за определенную дату.

Обработка и расчеты произведены с использованием программного комплекса QGIS. Ландшафтная структура приводится по ландшафтно-типологической карте Г.Е. Гришанкова [15] (рис. 1).

\section{Результаты исследования и их обсуждение}

В результате исследования для территории Бахчисарайского района Республики Крым получены значения вегетационного индекса NDVI за 2020 г. (рис. 2) на выбранные даты, имеющие минимальное облачное покрытие.

Как видно из рис. 2, максимальные значения NDVI характерны для юго-восточной части Бахчисарайского района, где сосредоточены природные лесные экосистемы, в то время как минимальные - для северо-западной части, где активно ведется хозяйственная деятельность и на сельскохозяйственных полях еще не наступила активная фаза вегетации и центральной части, где проходят основные магистрали и расположены крупные населенные пункты. В то же время, если рассматривать сезонную динамику, то в летние месяцы наблюдаются максимальные значения NDVI, которые достигают в юго-восточной части Бахчисарайского района значений более 0,8 . Анализ значений NDVI показывает, что максимальные значения наблюдаются в пределах групп местной с естественной непреобразованной растительностью.

Особый интерес представляет распределение значений NDVI в пределах групп местностей ландшафтов в пределах Бахчисарайского района Республики Крым. На рис. 3 представлена карта средних значений вегетационного индекса NDVI в пределах Бахчисарайского района Республики Крым для групп местностей. 


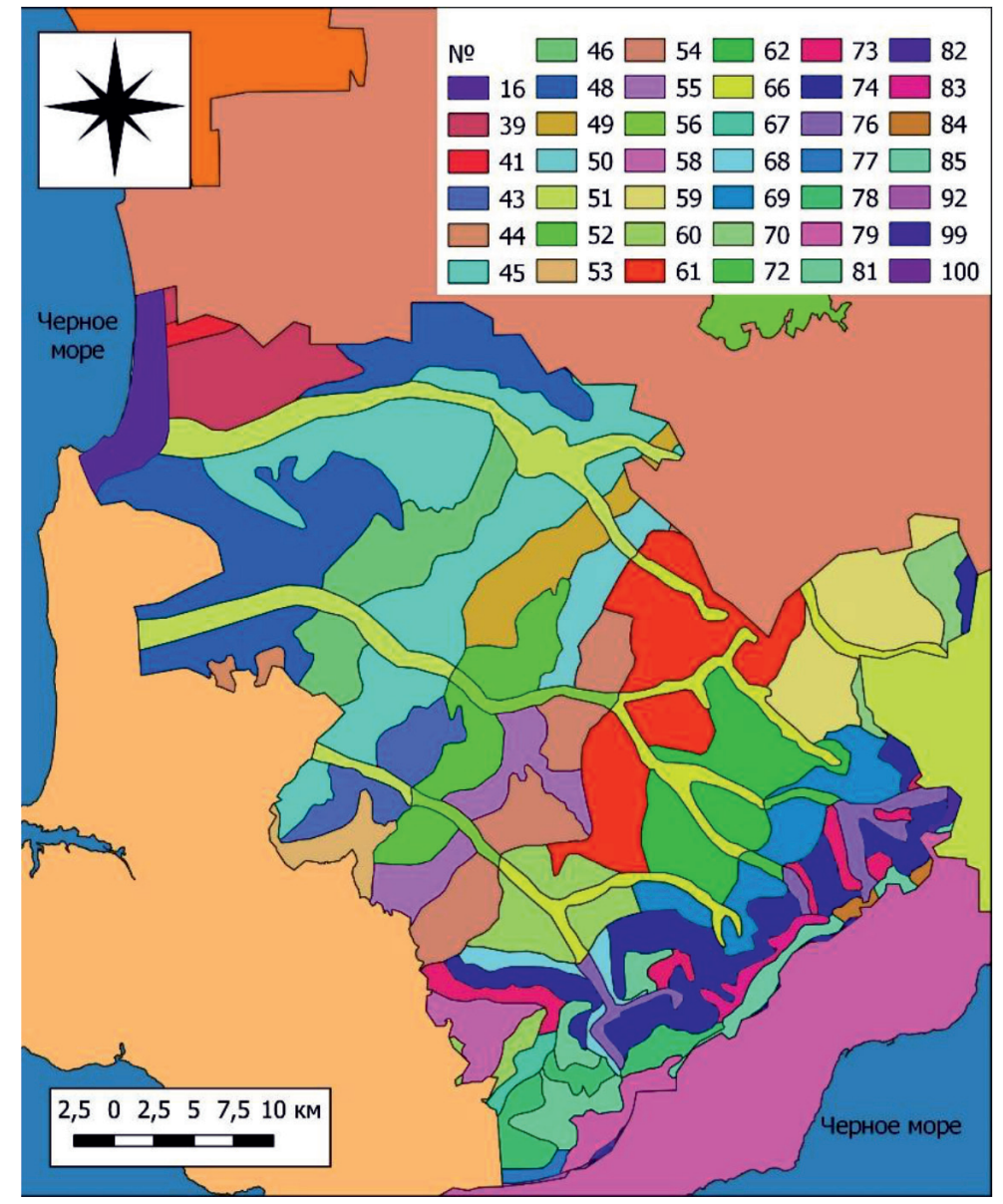

Рис. 1. Фрагмент ландшафтно-типологической карты Г.Е. Гританкова на территорию Бахчисарайского района Республики Крым (номера ландшафтов приводятся согласно [15])

Как можно видеть из рис. 2, в пределах групп местностей наибольшие средние значения вегетационного индекса NDVI приходятся на группы местностей среднегорно-склонового пояса дубовых, можжевелово-дубовых и смешанных широколиственных лесов. Если рассматривать значение NDVI в пределах восстановленных ландшафтов, представленных на территории Бахчисарайского района, то этот вегетационный индекс косвенно показывает преобразованность ландшафтного контура, ввиду того, что значительно увеличивается неоднородность распределения NDVI. Например, группа местностей денудационно-останцовые равнины с разнотравными степями, зарослями типа «дубки» и колючекустарниковыми зарослями типа «шибляк» характеризуется средними значениями NDVI, которые меньше, чем в большинстве других групп местностей в пределах пояса лесостепи на останцово-денудационных, структурных денудационных и аккумулятивных равнинах, куэстовых возвышенностях, ввиду того что по ней проходит большая часть дорожной инфраструктуры, связывающая Симферополь и Севастополь, а также расположены населенные пункты. На рис. 4 представлен график изменения вегетационного индекса NDVI за рассматриваемый период, из которого видно, что максимальные значения присутствуют практически в течение всего года для контуров с лесной растительностью, а минимальные - для контуров, где активно идет хозяйственное использование территории и выращивают сельскохозяйственные культуры.

Мониторинг температуры поверхности, выполненный на основании космических снимков Landsat-8, представлен на рис. 5. 


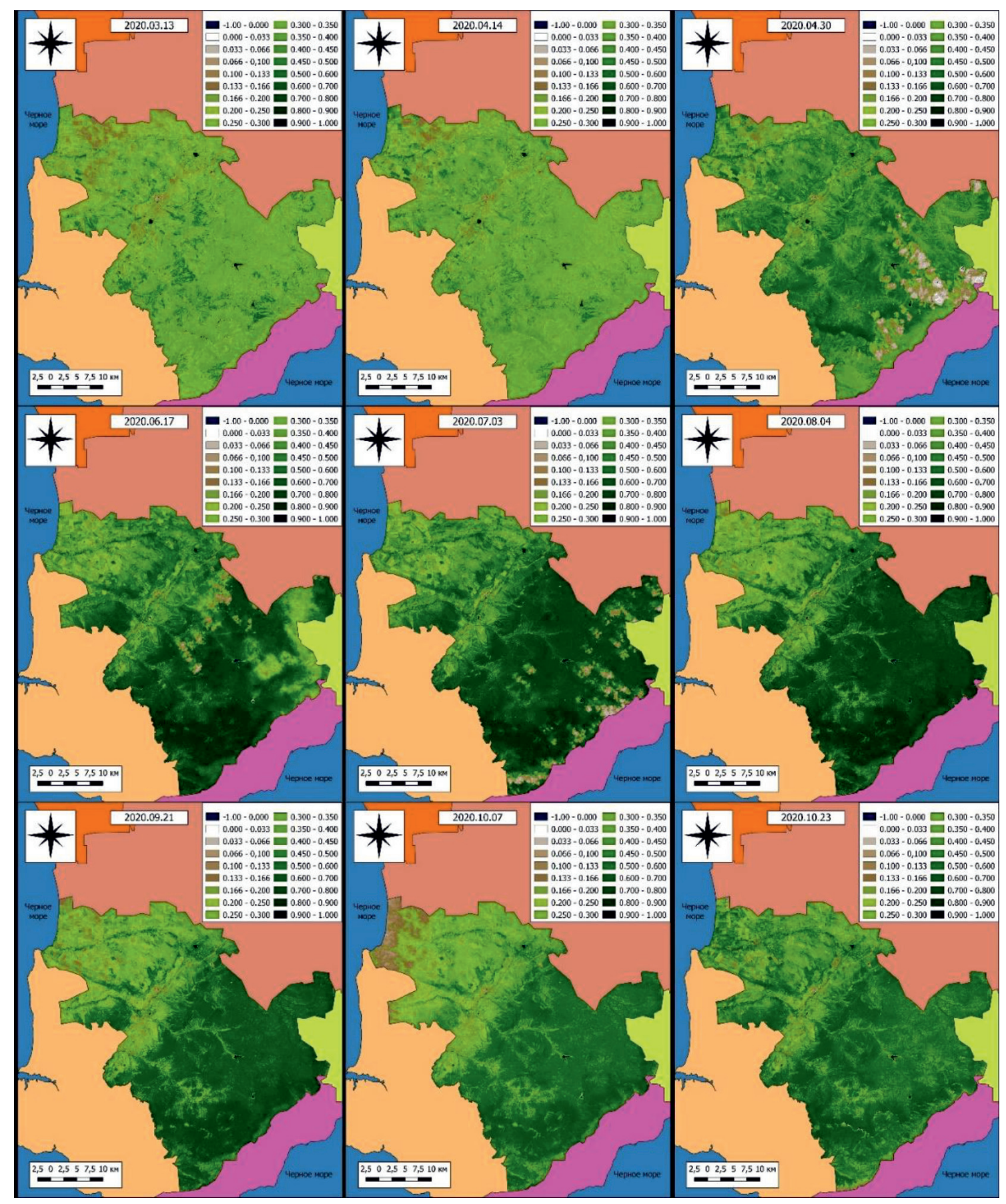

Pис. 2. Значение вегетационного индекса NDVI за 2020 г. в пределах Бахчисарайского района Республики Крым

Для анализа температуры поверхности, как и вегетационного индекса NDVI, снимки за 30 апреля 2020 г., 17 июня 2020 г., 03 июля 2020 г. и 07 октября 2020 г. подходят частично, так как имеют минимальное перекрытие облаками. Как видно из рис. 4 , в пределах Бахчисарайского района Республики Крым максимальные температуры поверхности характерны для северо-запада, где имеется большое количество открытых участков, а минимальные - для юго-восточной части района, где преобладают леса. 


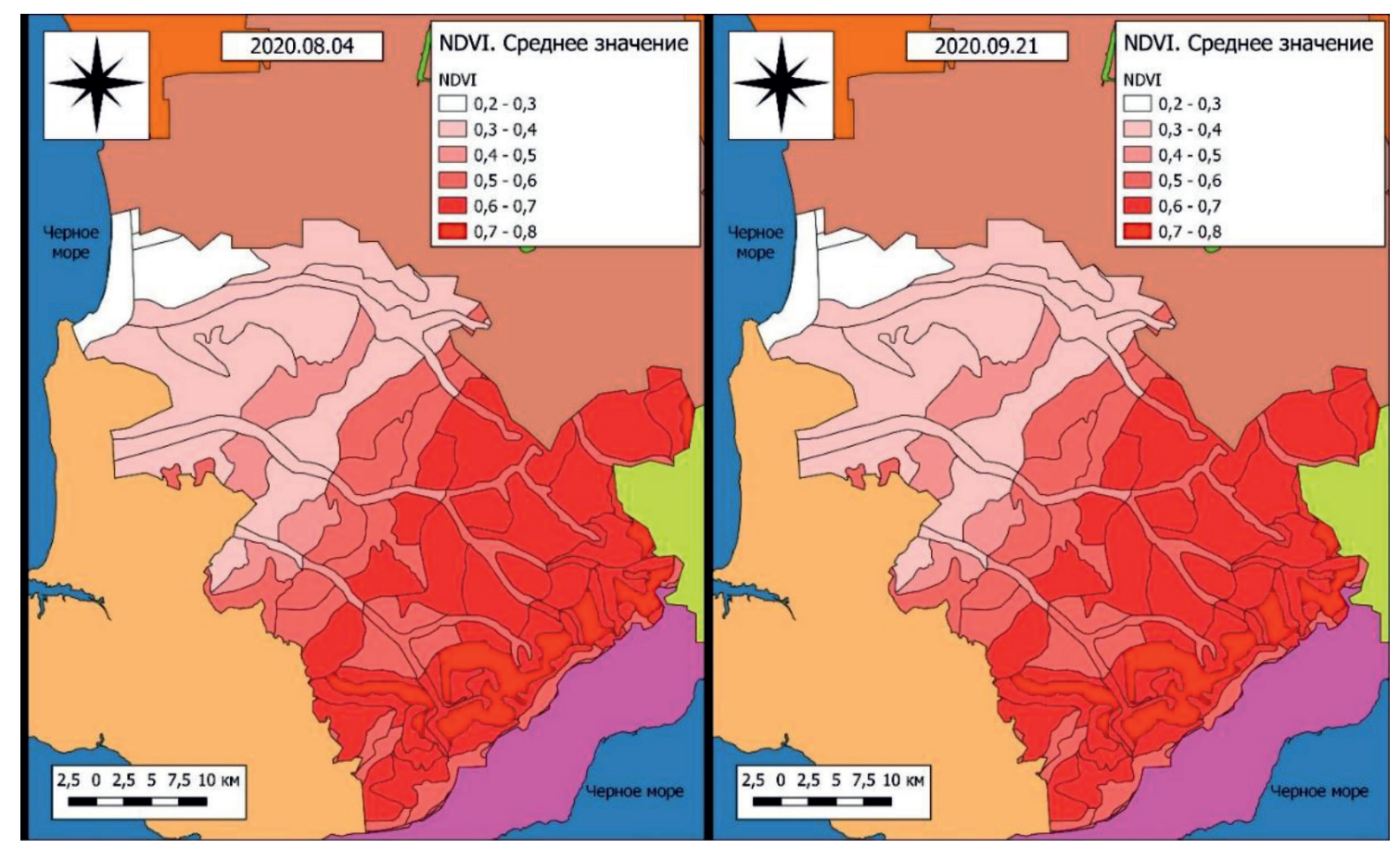

Рис. 3. Средние значения NDVI в пределах групп местностей на ландмафтно-типологической карте в пределах Бахчисарайского района Республики Крым

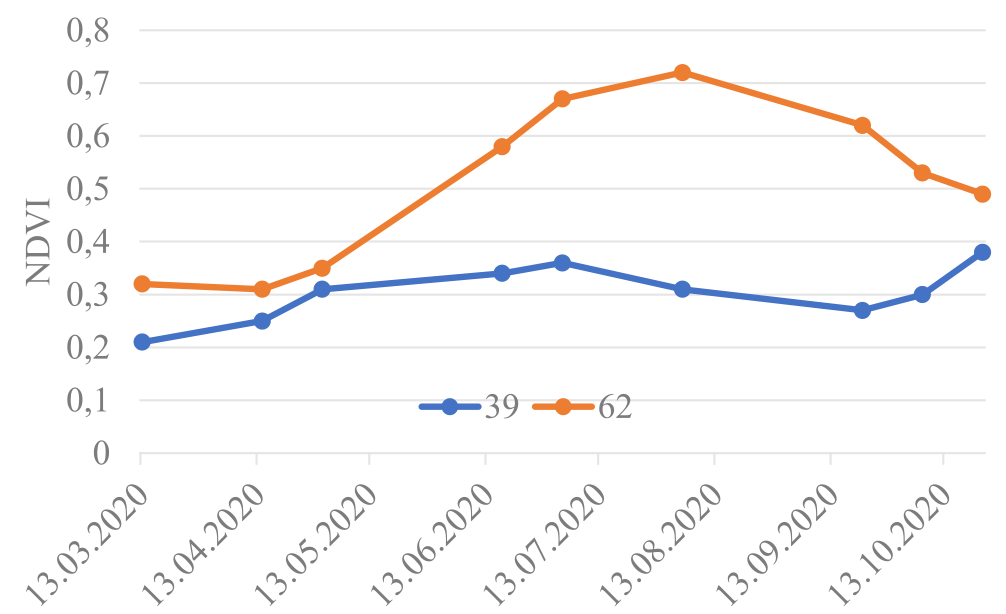

Рис. 4. Динамика изменения вегетаиионного индекса NDVI в пределах группь местностей № 39 (денудационно-останиоовые и аккумулятивные равнины с ковыльно-типчаковыми степями) и № 62 (эрозионное овражно-балочное низкогорье с дубовыми лесами и лесокустарниковыми зарослями)

К тому же существенный вклад в уменьшение температуры поверхности с северовостока на юго-запад вносит увеличение абсолютных высот. Наибольшую наглядность показывает рис. 6, где представлено распределение средних температур поверхности в пределах групп местностей, где вышеуказанная закономерность отчетливо видна. Расчет коэффициента корреляции между средними значениями абсолютной высоты и температуры поверхности в пределах групп местностей показал значения $-0,85$ для 04 августа 2020 г. и $-0,82$ для 21 сентября 2020 г., что свидетельствует 
о наличии высокой отрицательной связи между абсолютной высотой и температурой поверхности.

В то же время корреляционный анализ показывает наличие очень высокой обрат- ной отрицательной связи между средними значениями NDVI и температурой поверхности. Для 04 августа 2020 г. коэффициент корреляции составляет -0,92, а для 21 сентября 2020 г. составляет $-0,91$.

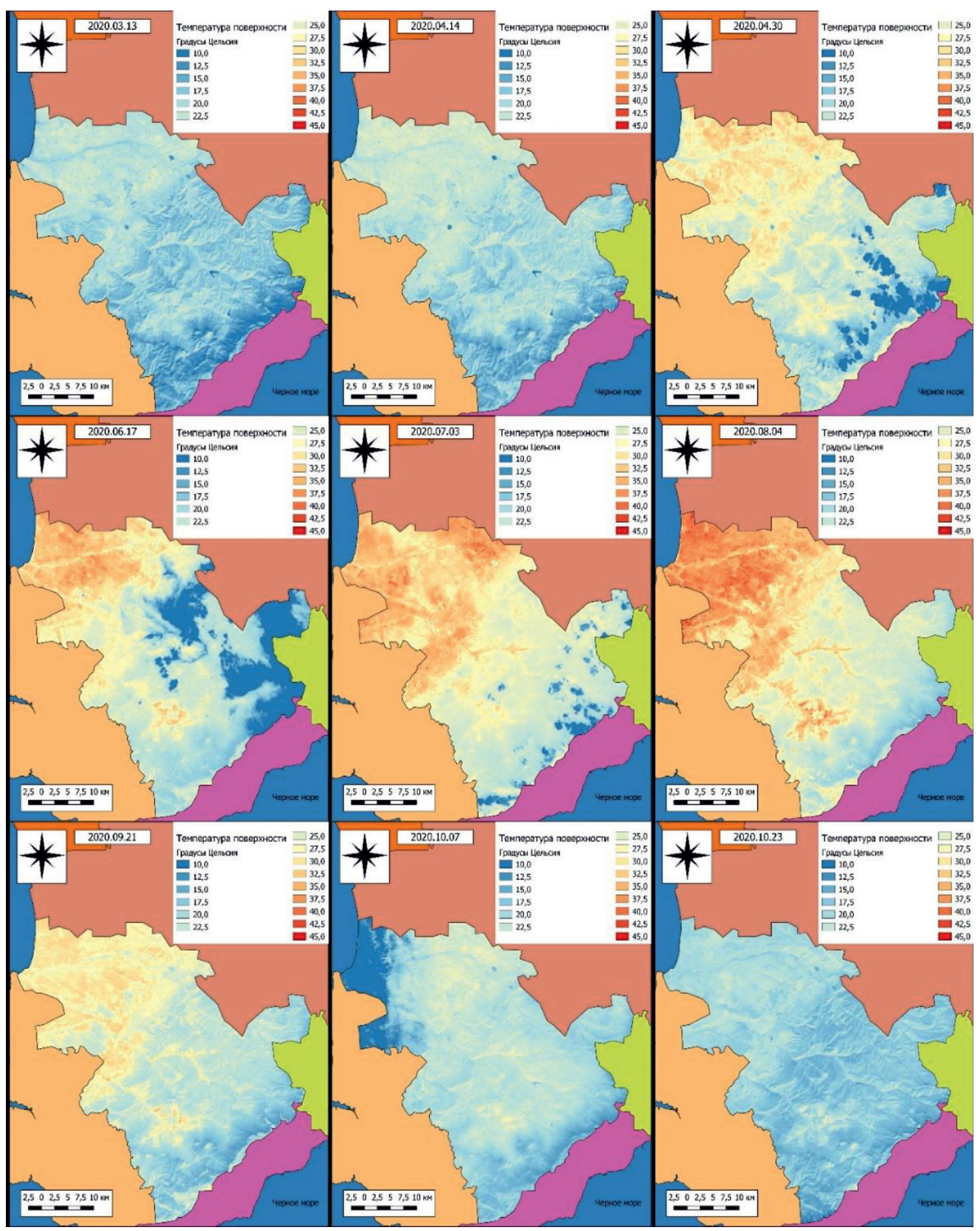

Рис. 5. Значение температуры поверхности (LST) за 2020 г. в пределах Бахчисарайского района Республики Крым 


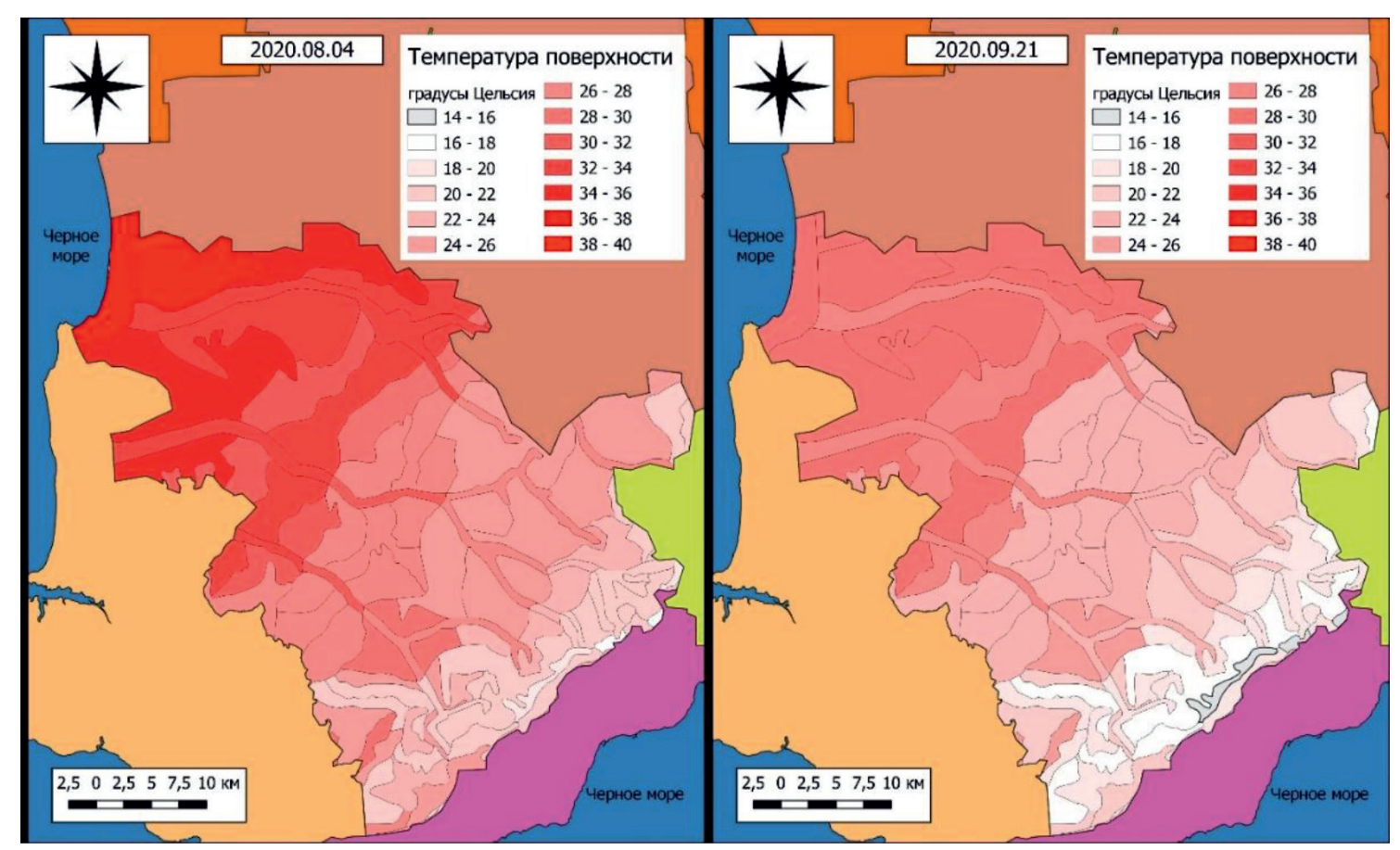

Рис. 6. Среднее значение температуры поверхности в пределах групп местностей на ландшафтно-типологической карте в пределах Бахчисарайского района Республики Крым

Таким образом можно говорить, что распределение вегетационного индекса NDVI и температуры поверхности (LST) носит квазизональный характер и нарушается только в пределах участков, где территория активно преобразована и используется в хозяйственной деятельности (населенные пункты, транспортная инфраструктура, земли сельскохозяйственного использования) и отчетливо выделяется при мониторинге.

\section{Заключение}

Использование космических снимков высокого разрешения позволяет вести мониторинг различных территорий, в том числе и ландшафтов и экосистем, при условии отсутствия данных полевых натурных исследований и слабом покрытии территории Крымского полуострова сетью метеостанций. Полученные данные репрезентативны и позволяют оценивать современное состояние и динамику различных показателей для исследуемых территорий. В результате исследования установлено, что на территории Бахчисарайского района Республики Крым значения вегетационного индекса NDVI увеличиваются, а температуры по- верхности уменьшаются с северо-запада на юго-восток, что связано с увеличением абсолютных высот и уменьшением антропогенной преобразованности территории.

Исследование выполнено в рамках темы НИР «Изучение пространственновременной организации водных и сухопутныхх экосистем с иеелью развития системь оперативного мониторинга на основе данных дистанционного зондирования и ГИСтехнологий. Регистрационный номер: 121040100327-3».

\section{Список литературы / References}

1. Каниболоцкая Ю.М., Толсужанова А.Т. Мониторинг окружающей среды и геоинформационные систем. Павлодар: Кереку, 2015. 137 с.

Kanibolotskaya Yu.M., Tolsuzhanova A.T. Environmental monitoring and geoinformation systems. Pavlodar: Kereku, 2015. 137 p. (in Russian).

2. Golubeva E.I., Kashirina E.S., Novikov A.A., Glukhova E.V. Using the NDVI index for geo-ecological estimation of specially protected natural territories by the example of Sevastopol. InterCarto, InterGIS. 2019. Vol. 25. № 1. P. 320-331. DOI: 10.35595/2414-9179-2019-1-25-320-331.

3. Zeshan M.T., Mustafa M.R.U., Baig M.F. Monitoring Land Use Changes and Their Future Prospects Using GIS and ANN-CA for Perak River Basin, Malaysia. Water. 2021. Vol. 13. No. 16. P. 2286. DOI: 10.3390/w13162286.

4. Dzhalilova G., Mamatkulov, F., Mamatkulova Z., Igamberdieva D., Eshquvatov Q. Long-term monitoring of the vegetation cover of mountain territories in the GIS for soil and 
landscape study of territories. E3S Web of Conferences. 2021. Vol. 264. P. 01004. DOI: 10.33619/2414-2948/64/03.

5. Солодков Н.Н., Молчанов О.М. Мониторинг зарастания неиспользуемых сельскохозяйственных земель на основе ГИС-технологий // Вестник Башкирского государственного аграрного университета. 2019. № 4 (52). C. 48-53. DOI: 10.31563/1684-7628-2019-52-4-48-54.

Solodkov N.N., Molchanov O.M. Monitoring overgrowth of unused agricultural lands based on GIS technologies// Vestnik Bashkirskogo gosudarstvennogo agrarnogo universiteta. 2019. № 4 (52). P. 48-53. DOI: $10.31563 / 1684-7628-2019-52-$ 4-48-54 (in Russian).

6. Tabunschik V.A. The distribution of the values of the NDVI on the territory of the Razdolnensky district of the Republic of Crimea in January-June 2018. Geopolitics and ecogeodynamics of regions. 2019. № 2. Р. 225-242.

7. Каширина Е.С., Новиков А.А., Голубева Е.И., Новикова А.М. Оценка уровня озеленения г. Севастополя по данным дистанционного зондирования Земли // Системы контроля окружающей среды. 2020. № 2 (40). C. 108-116. DOI: 10.33075/2220-5861-2020-2-108-116.

Kashirina E.S., Novikov A.A., Golubeva E.I., Novikova A.M. Assessment of the level of landscaping in Sevastopol according to the data of remote sensing of the earth // Sistemy kontrolya okruzhayushchey sredy. 2020. № 2 (40). P. 108-116. DOI: 10.33075 / 2220-5861-2020-2-108-116 (in Russian).

8. Yuan F., Bauer M.E. Comparison of impervious surface area and normalized difference vegetation index as indicators of surface urban heat island effects in Landsat imagery. Remote Sensing of environment. 2007. Vol. 106. № 3. P. 375386. DOI: $10.1016 /$ j.rse.2006.09.003.

9. Chen J.M., Cihlar J. Retrieving leaf area index of boreal conifer forests using Landsat TM images. Remote sensing of Environment. 1996. Vol. 55. № 2. C. 153-162. DOI: 10.1016/0034-4257(95)00195-6.
10. Табунщик В.А., Петлюкова Е.А., Хитрин М.О. Применение спутниковых снимков Sentinel-2 для анализа земель, используемых в сельском хозяйстве (на примере Раздольненского района Республики Крым) // Труды Карадагской научной станции им. Т.И. Вяземского - Природного заповедника РАН. 2018. № 1 (5). С. 43-57.

Tabunschik V.A., Petlyukova E.A., Khitrin M.O. The use of satellite imagery Sentinel-2 for analysis of land used in agriculture (for example Razdolnensky district of the Republic of Crimea) // Trudy Karadagskoy nauchnoy stantsii im. T.I. Vyazemskogo - Prirodnogo zapovednika RAN. 2018. № 1 (5). P. 43-57 (in Russian).

11. Weng Q., Lu D., Schubrin J. Estimation of land surface temperature-vegetation abundance relationship for urban heat island studies. Remote Sensing of Environment. 2004. Vol. 89. P. 467-483.

12. Svidzinska D., Korohoda N. Study of spatiotemporal variations of summer land surface temperature in Kyiv, Ukraine using Landsat time series. Geoinformatics: Theoretical and Applied Aspects. 2020. Vol. 2020. № 1. P. 17376. DOI: 10.3997/2214-4609.2020geo106.

13. Jiang Y., Lin W. A Comparative Analysis of Retrieval Algorithms of Land Surface Temperature from Landsat-8 Data: A Case Study of Shanghai, China. International Journal of Environmental Research and Public Health. 2021. Vol. 18. № 11. P. 5659. DOI: 10.3390/ijerph18115659.

14. Shevchuk S.A., Vyshnevskyi V.I. Using of Landsat 8 Satellite Data for Determinination of Microclimatic Peculiarities of Kyiv. Ukrainian journal of remote sensing. 2016. Vol. 10. P. 4-9.

15. Позаченюк Е.А. Современные ландшафты Крыма и сопредельных акваторий. Симферополь: Бизнес-Информ, 2009. 672 c.

Pozachenyuk E.A. Modern landscapes of the Crimea and adjacent water areas. Simferopol: Biznes-Inform, 2009. 672 p. (in Russian). 